DOCTRINA

\title{
Cumplimiento y ejecución de las sentencias de la Corte Interamericana de Derechos Humanos: Algunas reflexiones a partir del proceso de reforma en el Sistema Europeo de Derechos Humanos
}

\author{
Fulfilment and enforcement of the judgments of the Inter-American Human Rights
} Court: Some reflections from the reform process in the European Human Rights System

\author{
Oliver López \\ Universidad de El Salvador
}

\begin{abstract}
RESUMEN El artículo valora a la Declaración Americana sobre Derechos y Deberes del Hombre y la Convención Americana sobre Derechos Humanos como la base política, jurídica e institucional en la que descansa el Sistema Interamericano de Derechos $\mathrm{Hu}$ manos, el cual ha servido de guía del derecho americano en evolución a partir de una mayor interacción entre los niveles nacional e internacional. Señala el problema de la falta de cumplimiento y ejecución total de las sentencias de la Corte IDH como uno de los desafíos actuales del Sistema Interamericano. Para ello visualiza oportunidades en el proceso de reforma iniciado en el ámbito europeo, tales como potenciar la responsabilidad compartida para superar los problemas de eficacia en el cumplimiento de las sentencias, adoptar un mecanismo de subsidiariedad que le permita a los Estados contar con cierta libertad en adoptar medidas de reparación que se ajusten a las realidades nacionales, así como reforzar la capacidad nacional para ejecutar sentencias con la emisión de leyes específicas.
\end{abstract}

PALABRAS CLAVE Sistema Interamericano de Derechos Humanos, Corte Interamericana de Derechos Humanos, cumplimiento y ejecución de sentencias internacionales.

ABSTRACT The article values the American Declaration on the Rights and Duties of Man and the American Convention on Human Rights as the political, legal and institutional basis on which the Inter-American Human Rights System rests, which has served as a guide to American law in evolution from greater interaction between the national and international levels. It points out the problem of the lack of compliance and total execution of the judgments of the Inter-American Court as one of the current challenges of the Inter-American System. To do so, it visualizes opportunities in the process 
of reform initiated at the European level, such as strengthening shared responsibility to overcome the problems of effectiveness in compliance with judgments, adopting a subsidiarity mechanism that allows States to have a certain amount of freedom in adopt measures of reparation that adjust to national realities, as well as strengthen the national capacity to execute sentences with the issuance of specific laws.

KEYWORDS Inter-American Human Rights System, Inter-American Court of Human Rights, enforcement and execution of international sentences.

\section{Introducción}

En 2018 se conmemoraron 70 años desde la aprobación de la Declaración Americana sobre Derechos y Deberes del Hombre ${ }^{1}$ y 40 años de la entrada en vigor de la Convención Americana sobre Derechos Humanos (CADH). ${ }^{2}$ Ambos instrumentos jurídicos, junto con la Carta de la Organización de Estados Americanos (OEA), fijaron la base política, jurídica e institucional del Sistema Interamericano de Protección de los Derechos Humanos (SIDH). En los preámbulos de estos instrumentos encontramos la naturaleza de la protección internacional de los derechos humanos, la cual es «convencional coadyuvante o complementaria de la que ofrece el derecho interno de los Estados americanos»; funciona como "guía principalísima del derecho americano en evolución», y debe ser «fortalecida cada vez más en el campo internacional, a medida que las circunstancias sociales y jurídicas sean más propicias».

Hoy en día, el derecho internacional de los derechos humanos se ha posicionado como un régimen autónomo a partir de la fragmentación del derecho internacional (Koskenniemi, 2006: 96). En particular, en el ámbito interamericano se han adoptado nuevos instrumentos jurídicos que amplían y especifican los derechos protegidos, así como la formación de una rica doctrina y jurisprudencia. A nivel interno, la progresiva apertura de los sistemas nacionales al derecho internacional ha llevado a que las personas tengan mayor conocimiento de sus derechos y sus medios de protección, obteniendo sentencias aun cuando los Estados no estén de acuerdo con ellas (Pinto, 2010). Este es un aspecto crucial de la forma en que los derechos humanos funcionan en el mundo de hoy (Raz, 2009: 18).

No obstante, al llegar a ese punto, las víctimas protagonistas del procedimiento internacional comienzan otro camino para hacer efectivas las sentencias internacionales, cuyo cumplimiento le corresponde exclusivamente a los Estados. En el contex-

1. Aprobada el 30 de abril de 1948, por una resolución de la Novena Conferencia Internacional Americana, en Bogotá, Colombia.

2. Adoptada en San José, Costa Rica, el 22 de noviembre de 1969, en la Conferencia Especializada Interamericana sobre Derechos Humanos. Entrada en vigor el 18 de julio de 1978. 
to latinoamericano, ocurre el fenómeno denominado «brecha de la implementación» (Von Bogdandy, 2016: 12) en materia de derechos humanos, el cual consiste en que la mayoría de los Estados han incorporado a su legislación nacional las normas internacionales derechos humanos y han creado mecanismos de protección, pero no es suficiente para hacer efectivos los derechos en el ámbito local. Así, los Estados no son muy diligentes en satisfacer las obligaciones internacionales asumidas de forma voluntaria y postergan de manera indefinida su cumplimiento.

El presente artículo aborda el problema de la falta de cumplimiento y ejecución total de las sentencias de la Corte Interamericana de Derechos Humanos (Corte IDH) como uno de los desafíos actuales del Sistema Interamericano. Compartimos la idea de que pese a que las sentencias emitidas por la Corte IDH son definitivas, inapelables y cuentan con carácter vinculante para el Estado parte del caso en particular (artículos 67 y 68.1), el cumplimiento de las sentencias y el sistema de responsabilidad internacional se inserta en una reglamentación jurídica internacional, en la que tales decisiones carecen de imperio al interior de los Estados partes de la CADH que han reconocido su competencia contenciosa. Asimismo, la Corte IDH tampoco tiene competencia para ejecutar o hacer cumplir lo que resuelve, ${ }^{3}$ a menos que los Estados lo hayan dispuesto de esa forma en su derecho interno.

Este trabajo menciona algunas lecciones que ha arrojado el proceso de reforma del Sistema Europeo de Derechos Humanos (SEDH), que ha favorecido la eficacia en el cumplimiento de las sentencias del Tribunal Europeo de Derechos Humanos (TEDH), y propone perfeccionar el mecanismo de supervisión de sentencias del SIDH en dos direcciones: llenar el vacío de la normativa convencional en la materia con la creación de un órgano permanente de carácter político con representación de todos los Estados, e impulsar en los ordenamiento jurídicos nacionales la aprobación de leyes específicas y una institucionalidad que se encargue de la ejecución de las sentencias internacionales.

\section{Estado de la situación}

Hace dieciséis años, el entonces juez de la Corte IDH Antônio Cançado Trindade señaló que existían tres problemas que debían atenderse para fortalecer el SIDH: i) que todos los Estados miembros de la OEA ratifiquen la $\mathrm{CADH}$; ii) acepten integralmente la competencia contenciosa de la Corte IDH, e iii) incorporen las normas sustantivas de la CADH en su derecho interno a modo de asegurar la aplicabilidad directa de las normas convencionales y el fiel cumplimiento de las decisiones de la Corte IDH (Cançado Trindade, 2003: 76-77).

3. Voto individual del Juez Eduardo Vio Grossi, Corte IDH, opinión consultiva OC-24/17, 24 de noviembre de 2017, solicitada por la República de Costa Rica. Identidad de género, e igualdad y no discriminación a parejas del mismo sexo, párrafo 170. 
Al hacer un balance actual de estos criterios, la mayoría de los Estados han aceptado la CADH y la competencia contenciosa de la Corte IDH; ${ }^{4}$ sin embargo, varios Estados no han ratificado la $\mathrm{CADH}$, y cerca de un tercio no ha aceptado aún la competencia contenciosa de la Corte IDH, ${ }^{5}$ o han establecido declaraciones o reservas que limitan la jurisdicción del referido Tribunal Interamericano, por lo que las eventuales violaciones a derechos humanos solo podrían ser conocidas por la $\mathrm{CIDH}$ con base en la Declaración Americana sobre Derechos y Deberes del Hombre. Asimismo, son pocos los Estados latinoamericanos que son parte de todos los tratados de derechos humanos, sin reservas ni declaraciones interpretativas. ${ }^{6}$ Esa situación produce importantes asimetrías entre los Estados y le resta fortaleza al propio SIDH (Shelton y Carroza, 2013: 996).

Respecto de la incorporación de normas para implementar las sentencias interamericanas, son limitados los países en la región latinoamericana que cuentan con una normativa que ejecute sus decisiones. ${ }^{7}$ La mayoría de los países no cuentan con legislación específica local que señalen con claridad el procedimiento que hay que seguir para implementar y ejecutar las medidas ordenadas por la Corte IDH. En el caso de los ordenamientos europeos, si bien no se han desarrollado de manera amplia para darle mayor eficacia a los fallos del TEDH, es sin embargo frecuente el cumplimiento de sus decisiones, y solo cuando este cumplimiento no es satisfactorio, el propio TEDH establece una indemnización equitativa en beneficio del afectado.

En los últimos quince años, si bien se reportan aumentos importantes del nivel de cumplimiento de las sentencias interamericanas, sobre todo a nivel de cumplimiento parcial, los porcentajes de cumplimiento total se mantienen bajos. En una tendencia progresiva, para el 2006, el entonces juez de la Corte IDH, Sergio García Ramírez, informó a la Asamblea General de la OEA que solo el 10\% del total de casos con-

4. Actualmente, de los 34 Estados miembros de la OEA, 25 países han ratificado o se han adherido a la CADH: Argentina, Barbados, Bolivia, Brasil, Colombia, Costa Rica, Chile, Dominica, Ecuador, El Salvador, Granada, Guatemala, Haití, Honduras, Jamaica, México, Nicaragua, Panamá, Paraguay, Perú, República Dominicana, Surinam, Trinidad y Tobago, Uruguay y Venezuela. Trinidad y Tobago denunció la CADH el 26 de mayo de 1998. Venezuela denunció la CADH el 10 de septiembre de 2012. De éstos, solo 20 países han reconocido la competencia contenciosa de la Corte IDH: Argentina, Barbados, Bolivia, Brasil, Chile, Colombia, Costa Rica, Ecuador, El Salvador, Guatemala, Haití, Honduras, México, Nicaragua, Panamá, Paraguay, Perú, República Dominicana, Surinam y Uruguay.

5. Es el caso de Antigua y Barbuda, Bahamas, Belice, Canadá, Cuba, Estados Unidos, Guyana, San Kitts y Nevis, San Vicente y las Granadinas, Santa Lucía, Granada, Jamaica y Dominica, que son parte de la $\mathrm{CADH}$, pero no han reconocido la competencia contenciosa de la Corte IDH. Dos países han denunciado la CADH: Trinidad y Tobago y Venezuela.

6. Es el caso de Costa Rica, Ecuador, Panamá y Paraguay. Carlos Castilla Juárez, «¿Qué tan común es lo común del ius constitutionale commune Latinoamericano?», Ventana Jurídica, 21 de junio de 2017, disponible en http://bit.ly/2F8N31G.

7. Es el caso de Perú, Colombia y México (Landa, 2017). 
tenciosos estarían cumplidos. ${ }^{8}$ Luego, dos investigaciones independientes habrían determinado que el anterior porcentaje se habría incrementado, para el 2010, a $32 \%$ (Bertoni, 2010: 10), y, en el 2016, a 36,8\% (Basch y otros, 2010). Esta tendencia habría disminuido en forma considerable, a partir de otro estudio independiente elaborado en el 2016, que demostró que entre las sentencias dictadas por la Corte IDH en el período entre 2001 y junio de 2013, que involucra resoluciones de supervisión de la Corte IDH hasta junio de 2015 , el $88 \%$ no se había cumplido totalmente (Zaverucha y Leite, 2016).

Esta situación también ha sido confirmada por el juez Vio Grossi, con datos del informe anual 2016 de la Corte IDH, el cual destaca la ineficacia de la teoría del control de convencionalidad como mecanismo para cumplir sentencias:

De los 203 fallos de fondo que ha dictado la Corte, si bien 25 han sido archivados por cumplimiento total de lo fallado [12,3\%], 168 se encuentran bajo el sistema de supervisión de sentencias por no habérseles dado cumplimiento total $[82,8 \%]$ y otros 15 han sido informadas a la Asamblea General de la OEA en aplicación del artículo 65 de la Convención $[7,4 \%] .{ }^{9}$

Las medidas que son por lo general cumplidas son las compensaciones económicas y las simbólicas; no obstante, se mantienen brechas importantes en reparaciones no pecuniarias como reformas legales e investigación y sanción a trasgresores de violaciones a derechos humanos (Bertoni, 2016: 17). Frente a este escenario, hay posiciones que tratan de encontrar aspectos positivos a partir del cambio de comportamiento de los Estados por los fallos de los tribunales internacionales. Esta postura intenta superar la visión de que la eficacia solamente se puede medir a partir de la verificación completa de las medidas ordenadas por tales entes jurisdiccionales. En esta línea, se argumenta que esta eficacia es una cuestión de grado, en lugar de una proposición de todo o nada. En este escenario, se valoran los cumplimientos parciales de los fallos, los cuales han dado lugar a importantes cambios en la protección de los derechos humanos dentro de los países, situación que no habría sucedido sin que existiese una sentencia internacional.

No obstante, lo anterior significaría, por una parte, que no se ha hecho lo suficiente para dotar de efectividad a sus sentencias e intentar persuadir a los Estados a respetar las decisiones judiciales y cumplir las medidas de reparación ordenadas, en lo fundamental a través de un mecanismo eficaz de supervisión de cumplimiento de sentencias; y, por otra, que los Estados que son los garantes de los derechos humanos,

8. «Informe del presidente de la Corte Interamericana de Derechos Humanos ante la Asamblea General de La OEA», Corte Interamericana de Derechos Humanos, 5 de junio de 2007, disponible en https:// bit.ly/2QrlUfS.

9. Voto individual del juez Eduardo Vio Grossi, párrafo 171. 
manifiestan un desinterés en cumplir de forma integral con las decisiones del Tribunal Interamericano. Ambas implicaciones son graves para los intereses de las víctimas de acceder a una justicia internacional, quienes no encontrarían una instancia para hacer valer sus derechos, lo que deslegitima a ambos sistemas jurídicos.

También se cuentan con otros datos sobre la efectividad del SIDH. Si bien el número de sentencias emitidas han ido en aumento en los últimos años, la Corte IDH sigue recibiendo pocos casos por la CIDH y, por ende, la producción de sentencias es también baja. Así, para el 2017, solo 18 casos nuevos habrían sido sometidos a la Corte IDH, con un rezago de 35 casos por resolver; al final de ese año se notificaron 14 sentencias, ${ }^{10}$ para una cobertura de 20 Estados parte de la CADH que han ratificado la competencia de la Corte IDH, con una población aproximada de 581 millones de personas. ${ }^{11}$ Estos datos están muy lejos de igualarse a los reportados por el TEDH, ${ }^{12}$ que solo para el 2017, habría emitido 1.068 sentencias definitivas, con una cobertura de 47 Estados miembros, ${ }^{13}$ y una población total de más de 820 millones de personas.

Esta situación es un tanto diferente al desarrollo en el SEDH, el cual, a diferencia del SIDH, otorga un amplio margen de apreciación a los Estados en la búsqueda de soluciones legislativas y otras adaptadas a las circunstancias nacionales. Desde el 2010, los 47 Estados del Consejo de Europa iniciaron un proceso de reforma sobre la aplicación de la CEDH y la ejecución de las sentencias del TEDH. Este proceso ha implicado un refuerzo en la capacidad de los Estados para ejecutar sentencias con el fin de incrementar el diálogo constructivo y el sentido de responsabilidad compartida entre todos los involucrados, tanto a nivel nacional como en el Consejo de Europa. De esta reflexión han surgido nuevos protocolos que hacen más efectivo el SEDH, declaraciones políticas para mejorar su financiamiento, medidas para reforzar la subsidiariedad y, por lo tanto, la capacidad nacional para aplicar la CEDH y ejecutar las sentencias, entre otras. Los resultados positivos de esta reforma en los últimos años — para el 2017 cerró 3.691 casos en forma definitiva, de los 2.066 para el año 2016 (TEDH, 2017: 7) - se traduce en la buena acogida del sistema que establece la CEDH

10. Corte Interamericana de Derechos Humanos, «Informe anual 2017», p. 10. Disponible en https:// bit.ly/368U6mZ.

11. «World Urbanization Prospects 2018», Naciones Unidas, disponible en https://population.un.org/ wup/.

12. Cabe mencionar que el SEDH funciona con un solo órgano jurisdiccional el TEDH, luego de la entrada en vigor del Protocolo 11, en 1998, que eliminó a la Comisión Europea de Derechos Humanos. A partir de ese año, se ha experimentado un aumento extraordinario de quejas por presuntas violaciones a derechos humanos, problema que se ha ido reduciendo con el avance del proceso de reforma a profundidad de dicho sistema desde el 2010.

13. «Analysis of statistics 2017», Corte Europea de Derechos Humanos, enero de 2018, disponible en https://bit.ly/37nzeW4. 
por los Estados miembros, y apoya en buena medida al Consejo de Ministros, ente encargado del proceso de supervisión de ejecución de sentencias.

\section{La falta de imperio de las sentencias internacionales}

Uno de los principales retos en la actual transformación que experimenta el derecho público a partir de la apertura de los ordenamientos jurídicos internos al derecho internacional, es la búsqueda de mecanismos para dotar de eficacia a las sentencias de los tribunales internacionales de derechos humanos en el ámbito nacional, tomando en cuenta que éstos actúan de manera subsidiaria a los ordenamientos jurídicos nacionales, y necesitan de ellos para materializar las medidas de reparación que son ordenadas.

Esto es así porque, para el derecho internacional público, las sentencias internacionales en materia de derechos humanos carecen de imperio para exigir su cumplimiento (Santelices y Feddersen, 2010: 100), lo que no significa que no deban acatarse. Una vez que un tribunal internacional ha dictado una sentencia, la normativa convencional dispone que el Estado condenado tiene el deber de cumplir con el fallo (artículo 68.1 de la CADH). ${ }^{14}$ Esto se explica por la teoría del «desdoblamiento funcional» (Scelle, 1933: 358-359), que señala que el Estado que participe en la elaboración de normas internacionales, es el mismo que debe aplicar de forma interna la norma que ha creado; por tanto, el cumplimiento efectivo de las normas internacionales recae en la actuación estatal y el orden jurídico doméstico. Sin embargo, los tribunales internacionales no cuentan con los mecanismos jurídicos ejecutivos o coercitivos para ejercer una presión eficaz en los Estados (Londoño, 2006: 121) e impulsar el cumplimiento cuando éste no se produce en el plazo indicado.

En consecuencia, la tarea de determinar la forma de ejecutar el fallo recae inexcusablemente en los Estados, que cuentan con un margen de discreción para decidir los medios de ejecución. No obstante, esta regla general no se cumple siempre. Así, se presentan situaciones en que el TEDH no se limita a declarar solo la violación a derechos humanos, ${ }^{15}$ sino que en ciertos casos se encuentra habilitado para señalar una «satisfacción equitativa» cuando el derecho interno no logra dar cabal cumplimiento a sus decisiones. Por su parte, la Corte IDH ha interpretado de forma expansiva su facultad de reparar violaciones a derechos humanos: alejándose del paradigma de las sentencias declarativas, ha dictado medidas reparatorias no pecuniarias. En este sentido, la Corte IDH no es deferente con los Estados, ocupa una «versión débil del principio de subsidiariedad» (Jachtenfuchs y Krisch, 2016: 8), al presumir un umbral

14. También el artículo 26 de la Convención de Viena sobre el Derecho de los Tratados.

15. Sentencia del 13 de junio de 1979, Tribunal Europeo de Derechos Humanos, serie A volumen 31, párrafo 58 . 
bajo de lo local, contrario a la versión fuerte evidenciado por su par europeo (Contesse, 2016).

\section{La obligación de cumplir las sentencias internacionales y sus mecanismos de supervisión}

El significado que el derecho internacional le ha dado a la obligación de cumplimiento ha estado influenciada por la teoría de las normas como un estado de conformidad o identidad entre el comportamiento de un actor y una regla específica. Para el derecho internacional de los derechos humanos, el cumplimiento se logra mediante dos mecanismos: i) aplicación directa por parte de la judicatura, o mediante la adecuación de las normas nacionales al derecho internacional; e ii) implementación del derecho internacional de los derechos humanos, es decir, mediante la ejecución de decisiones judiciales de órganos internacionales (Mushkat, 2009: 163).

Esta segunda alternativa es el camino que ha seguido el SEDH, mecanismo internacional con mayor experiencia que sus pares regionales por su antigüedad, y que ha registrado una evolución importante a nivel sustantivo y procedimental con la adopción de una serie de protocolos al CEDH. ${ }^{16}$ Los Estados miembros del SEDH cuentan con la obligación positiva de cumplir con las sentencias definitivas del TEDH, que han encontrado trasgresiones al CEDH. En la etapa de ejecución de sentencias surge un aspecto que diferencia al SEDH, que lo vuelve más efectivo, ya que la labor de supervisión de la ejecución de las sentencias y decisiones del TEDH recae en el Comité de Ministros del Consejo de Europa, compuesto por representantes de los Estados miembros. Pese a que estos Estados tienen la obligación legal de remediar las violaciones declaradas, se les deja la elección de los medios equivalentes a utilizar en el orden jurídico interno para cumplir con las medidas ordenadas en el fallo. Las medidas a tomar son, en principio, identificadas por el Estado en cuestión, bajo la supervisión del Comité de Ministros.

El TEDH puede asistir al proceso de ejecución, en particular mediante el procedimiento de las «sentencias piloto», utilizado en caso de serios problemas estructurales, debiendo adoptar medidas individuales a favor de la víctima o de carácter general. El nivel de cumplimiento de los fallos del TEDH es mucho mayor que el SIDH (Leite,

16. En 1998, el Protocolo 11 reemplazó la estructura original de dos niveles, compuesta por la Comisión y el TEDH, que sesionaban algunos días al mes, por un único tribunal a tiempo completo. El Protocolo 14, en 2010, introdujo nuevas formaciones judiciales para los casos más simples y estableció un nuevo criterio de admisibilidad. El Protocolo 15, de 2013, inserta referencias al principio de subsidiariedad y la doctrina del margen de apreciación en el preámbulo de la CEDH. El Protocolo 16, de 2013, permite a las más altas cortes y tribunales nacionales solicitar a la TEDH que emita opiniones consultivas sobre cuestiones de principio relacionadas con la interpretación o aplicación de los derechos y libertades definidos en la CEDH o el protocolo a esto. Estos dos últimos protocolos no han entrado en vigor. 
2017: 117). Esto se debe que a que el SEDH se inserta en un modelo de protección multinivel de derechos humanos que incluye el derecho de integración económica y política, con asignación de funciones constitucionales al TEDH y a uno de sus entes intergubernamentales como encargado de velar, por la vía diplomática, por el cumplimiento de las sentencias, sin necesidad de acudir en principio al TEDH. Al corresponder la ejecución de la sentencia al Estado demandado, el efectivo cumplimiento de los pronunciamientos del TEDH tiene que insertarse en su ordenamiento interno, que puede, de manera provisoria, tener dispuesta la normativa que asegure el cumplimiento de las sentencias del TEDH. En defecto de una normativa legal que regule esta ejecución, la sentencia es cumplida por los canales legales que establezca el sistema jurídico nacional.

En el SIDH, la obligación de cumplir los fallos de la Corte IDH se encuentra en el artículo 68.1 de la CADH. Asimismo, de acuerdo con el artículo 67 de la CADH, estas sentencias son definitivas, inapelables y obligatorias, en virtud del reconocimiento de la competencia contenciosa de la Corte IDH que algunos Estados han hecho al momento de ratificar la CADH. La Corte IDH ha interpretado que, a partir de las anteriores normas, las sentencias deben ser prontamente cumplidas por el Estado en forma íntegra. Esta obligación corresponde a un principio básico del derecho de la responsabilidad internacional, según el cual los Estados deben atender sus obligaciones convencionales internacionales a partir de la buena fe y no alegar razones de orden interno para dejar de asumir la responsabilidad internacional ya establecida. ${ }^{17}$ Los Estados deben garantizar el cumplimiento de las disposiciones convencionales y sus efectos propios (effet utile) en el plano de sus respectivos derechos internos, ${ }^{18} \mathrm{el}$ cual incluye las normas sustantivas de los tratados de derechos humanos y las normas procesales, como las que se refieren al cumplimiento de las decisiones de la Corte IDH. ${ }^{19}$ De ahí que parte de la doctrina considere que la naturaleza dada a esta obligación es de resultado, es decir, exige determinar los medios a través de los cuales concreta y ejecuta las obligaciones emanadas de la sentencia (Nogueira Alcalá, 2006).

Pese a ese alcance normativo, no existe una norma convencional que permita ejecutar las decisiones contra los Estados, excepto aquella que se refiere a la parte del fallo que dispone una indemnización compensatoria. Así, el artículo 68.2 de la $\mathrm{CADH}$ solamente dispone el pago por indemnización a través de un procedimiento interno

17. Convención de Viena sobre el Derecho de los Tratados, adoptada el 23 de mayo de 1969, artículos 26 y 27. También caso Niños de la Calle (Villagrán Morales y otros), Corte IDH, cumplimiento de sentencia, 14 de junio de 2005, considerando 5 .

18. Sentencia del caso Hermanos Gómez Paquiyauri, Corte IDH, serie C núm. 110, 8 de julio de 2004, párrafo 151; sentencia del caso Baena Ricardo y otros con Panamá, competencia, serie C núm. 104, 28 de noviembre de 2003, párrafo 66; y sentencia del caso Bulacio, serie C núm. 100, 18 de septiembre de 2003, párrafos 117 y 142.

19. Sentencia del caso Ivcher Bronstein con Perú, Corte IDH, competencia, serie C núm. 54, 24 de septiembre de 1999, párrafo 37. 
vigente para la ejecución de sus sentencias, omitiendo un medio de implementación para otras formas de reparación no pecuniarias. Esta norma de reenvío al derecho interno hace que no sea necesario que el Estado dicte una normativa procesal especial que ejecute el fallo indemnizatorio emitido, la sentencia se vuelve exigible de manera automática (Rodríguez Rescia, 1998: 30-31).

De acuerdo con el artículo 65 de la CADH, la Corte IDH someterá a la Asamblea General de la OEA, de manera especial y con las recomendaciones pertinentes, los casos en que un Estado no haya dado cumplimiento a sus fallos, de modo que este mecanismo permite que un órgano político pueda discutir y adoptar una resolución al respecto, como puede ser el emitir un pronunciamiento público, hacer gestiones diplomáticas, suspender la membresía de un gobierno que depone a un régimen democrático, recomendaciones para imponer sanciones económicas, restricciones en los procesos de integración o conclusión de acuerdos económicos o préstamos, entre otras (Krsticevic, 2003: 24). Sin embargo, este mecanismo no ha resultado efectivo, pues la propia Corte IDH no lo ha utilizado de manera sistemática, debido a que las situaciones comunicadas a dicho organismo de la OEA no han cambiado (Leite, 2017: 113-117).

Una de las razones de la insuficiencia de este mecanismo es su base legal de funcionamiento. Los mandatos de los órganos políticos de la OEA involucrados para analizar cada uno de los casos y discutir el incumplimiento de las sentencias de la Corte IDH son implícitos, la presentación de observaciones y recomendaciones sobre los casos es una facultad y no una obligación; países que no han aceptado la jurisdicción de la Corte IDH forman parte de los órganos políticos que analizan las sentencias que no se están ejecutando; y los Estados no presionan a sus pares para cumplir con las obligaciones de los tratados de derechos humanos vinculados con el $\mathrm{SIDH}$, lo que incluye las sentencias de la Corte IDH. Esta presión ocurre de manera ocasional. Una de las explicaciones es que las violaciones de derechos humanos no han sido condición sujeta a ser objeto de sanciones internacionales.

Asimismo, la obligación incluye el deber del Estado de informar a la Corte IDH sobre las medidas adoptadas para cada uno de los puntos ordenados, que es fundamental para evaluar el estado de cumplimiento de la sentencia en su conjunto. ${ }^{20}$ En este sentido, al final de cada sentencia se agrega una cláusula en la que se establece el mandato de la Corte IDH de supervisar su cumplimiento íntegro, la cual quedará concluida una vez que el Estado haya dado cabal cumplimiento a lo dispuesto. Para que tenga sentido la obligación de cumplir y se logre proteger efectivamente los derechos declarados, ésta se complementa con la supervisión de la Corte IDH y los mecanismos efectivos internos para ejecutar las sentencias. Esta fase de ejecución no puede desligarse del procedimiento internacional y forma parte del derecho de acce-

20. Caso Familia Barrios con Venezuela, Corte IDH, supervisión de cumplimiento de sentencia, 2 de septiembre de 2015, considerando 2. 
so a la justicia, entendido en el sentido amplio, que abarca el cumplimiento pleno de las sentencias, con tal de no volver ilusorio el fin de protección del SIDH, y el derecho reconocido que se pretende hacer valer en el derecho interno.

La falta de eficacia del SIDH podría significar que en la etapa procesal de ejecución del cumplimiento de las sentencias de la Corte IDH, hay un rompimiento de la fórmula de igualdad de armas en el procedimiento internacional (Abregú y Espinoza, 2007), lo que afecta a las víctimas, que quedan desprotegidas por la inacción del Estado en la implementación de las medidas ordenadas por el Tribunal Internacional. El motivo de este desamparo es el vacío que existe en el derecho internacional y el derecho interno en la materia, el cual ha obligado a la Corte IDH a tratar de equilibrar esta relación de igualdad de posiciones por medio de vías procesales alternativas acudiendo a una interpretación de principios generales del derecho internacional, a la teoría de las funciones implícitas, ampliando su competencia e introduciendo figuras que no aparecen reguladas claramente en la normativa convencional.

En efecto, la competencia de la Corte IDH para supervisar el cumplimiento de sus decisiones no es atribuido de forma expresa por la CADH. En una lectura peculiar de la norma convencional, la Corte IDH ha inferido que cuenta con esa competencia. No obstante, esta interpretación es discutible, incluso en el mismo seno de la Corte IDH. Así, para el juez Eduardo Vio Grossi, a partir del artículo 68.1 de la CADH, la Corte IDH no cuenta con facultades supranacionales respecto de la supervisión del cumplimiento de sus sentencias. Estas facultades, al no haber sido contempladas en la $\mathrm{CADH}$, no pueden ser establecidas vía reglamento, o una sentencia o resolución de la Corte IDH. ${ }^{21}$ Pese a lo anterior, bajo el argumento de impulsar o incentivar el total cumplimiento de dichas sentencias, la Corte IDH decidió reformar su reglamento, e incluyó un mecanismo de supervisión de cumplimiento de sentencias y otras decisiones. Esta iniciativa busca reponer la igualdad de armas durante el procedimiento internacional, esta vez, en la fase de implementación de la sentencia. La Corte IDH tiene una nueva oportunidad para pronunciarse e intervenir sobre las medidas que el Estado se encuentra obligado a ejecutar; en esta instancia puede decidir si tales acciones han resultado suficientes para reparar a las víctimas, o en su caso, continuar con el seguimiento respectivo.

Esta supervisión no se le delega a otro ente técnico ni político dentro de la OEA, sino que es ejecutada directamente por la propia Corte IDH mediante un procedimiento escrito $\mathrm{u}$ oral, en el que se presentan informes estatales y observaciones de las víctimas o sus representantes. Esta competencia de supervisión que se ha atribuido la Corte IDH sobre sus propias decisiones no ha sido cuestionada por la Asamblea

21. Caso Artavia Murillo y otros («Fecundación in vitro») con Costa Rica, Corte IDH, supervisión de cumplimiento de sentencia, 26 de febrero de 2016, voto individual disidente del juez Eduardo Vio Grossi, párrafo 9. 
General de la OEA. El único pronunciamiento crítico de un Estado frente a esta situación fue el caso Baena Ricardo y otros con Panamá. En esa oportunidad, la Corte IDH declaró que "es competente para supervisar el cumplimiento de sus decisiones», que en ejercicio de su competencia «tiene facultad de solicitar a los Estados responsables la presentación de informes sobre las gestiones realizadas para dar aplicación a las medidas de reparación ordenadas por ella, de evaluar dichos informes, y de emitir instrucciones y resoluciones sobre el cumplimiento de sus sentencias». Por ello, decidió «Desestimar por improcedente el cuestionamiento» de su competencia para «supervisar el cumplimiento de sus sentencias expuesto por el Estado» y continuar supervisando «el cumplimiento integral de la sentencia». ${ }^{22}$

Posteriormente, en las resoluciones que ha emitido bajo el mecanismo de supervisión, la Corte IDH ha ampliado el sentido de las disposiciones de la CADH, en virtud del poder inherente que cuenta todo órgano con funciones jurisdiccionales, a fin de determinar el alcance de su propia competencia. La Corte IDH ha señalado que la supervisión del cumplimiento de las sentencias es uno de los elementos que componen su jurisdicción, por lo que tiene competencia para desplegar acciones para asegurar que sus decisiones no sean meramente declarativas, sino efectivas, de tal manera que el cumplimiento de las reparaciones ordenadas sean la materialización de la justicia para el caso concreto y de la jurisdicción. ${ }^{23}$ En esa línea, ha expresado que la efectividad de las sentencias depende de su ejecución. El proceso debe tender a la materialización de la protección del derecho reconocido en el pronunciamiento judicial mediante la aplicación idónea de dicho pronunciamiento. Añadió que la ejecución de estas decisiones y sentencias debe ser vista como parte integrante del derecho de acceso a la justicia, que entiende, en sentido amplio, que abarque también el cumplimiento pleno de la providencia pertinente. ${ }^{24}$

A partir del 2015, entró en funcionamiento la Unidad de Supervisión de Cumplimiento de Sentencias, adscrita a la Secretaría de la Corte IDH, dedicada en forma exclusiva a esta tarea. Antes de su creación, esta labor recaía en los equipos de trabajo del área legal de la Secretaría de la Corte IDH, quienes tenían a su cargo a su vez la elaboración de resoluciones en los otros mecanismos de protección estipulados en la CADH. Esta unidad apoya a la Corte IDH en la ejecución de audiencias, elaboración de resoluciones, diligencias in situ y estrategias de supervisión de sentencias. También forma parte del ejercicio de la función jurisdiccional de supervisar el cumplimiento de las sentencias de la Corte IDH, y la obligación de reintegrar al Fondo de Asistencia Legal de Víctimas la cantidad ordenada en las sentencias, cuando procediere. ${ }^{25}$

22. Baena Ricardo y otros con Panamá, párrafos 68 y ss.

23. Baena Ricardo y otros con Panamá, párrafos 72-73 y 92-93.

24. Baena Ricardo y otros con Panamá, párrafo 73.

25. Desde el 2010, se encuentra en funcionamiento el Fondo Legal de Asistencia de Víctimas de la 


\section{Razones que entrega la doctrina para adoptar un modelo de supervisión de cumplimiento de sentencias internacionales específico}

Como se ha dicho, el SIDH cuenta con un modelo de supervisión que deja poca deferencia a los Estados para elegir la manera en que dará cumplimiento a sus obligaciones internacionales. Desde ese enfoque, la propia Corte IDH es la encargada de velar por que se cumplan las sentencias internacionales. Por su parte, el SEDH abraza un modelo que reconoce una versión fuerte del principio de subsidiariedad y la doctrina del margen de apreciación nacional.

Desde un enfoque de la ejecución de sentencias internacionales, la doctrina se encuentra dividida respecto de la conveniencia de adoptar uno u otro modelo. En primer lugar, las críticas que recibe el modelo que no señala detalladamente las medidas de reparación (el que sigue el SEDH) son que al no hacer el ejercicio de especificar las reparaciones, quedaría menos sujeta a las negociaciones políticas; sería más fácil monitorear la ejecución con objetividad; y en caso de incumplimiento de la sentencia por parte de los órganos políticos, sería más fácil exigir su implementación a través del sistema jurídico interno, en tanto se trataría de una violación confirmada con autoridad de cosa juzgada (Greer, 2006: 160-161). Por otro lado, un aspecto positivo es que distingue entre medidas individuales y garantías de no repetición: las primeras serían más fáciles de cumplimiento por las que pueden estipularse en la sentencia; por el contrario, las segundas, el procedimiento de supervisión internacional establece un diálogo con el Estado a fin de encontrar las medidas que sean más adecuadas (Issaeva, Sergeeva y Suchkova, 2011).

En el segundo lugar, las críticas al modelo que sí señala las medidas de reparación (el que sigue el SIDH) son que las medidas que aseguren la no repetición de las violaciones pueden requerir reformas integrales; no se limitan a cambios legislativos, sino también a cambios en la práctica administrativa, en la opinión pública o en las actitudes de los funcionarios del Estado ante una práctica en particular; tiende a generalizar soluciones a casos que son muy complejos y que pueden orientar mal a los Estados respecto a las medidas a ser adoptadas; y que los procesos son lentos y costosos; entre otras (Issaeva, Sergeeva y Suchkova, 2011).

Un aspecto a considerar es que en el caso del SEDH, el proceso político de cumplimiento de sentencias puede ser instrumental para generar un sentido de propiedad para el cumplimiento de las medidas dictadas en la sentencia a nivel nacional. En

Corte IDH, creado por la Asamblea General de la OEA. Este es otro mecanismo que refuerza el trabajo de la Corte IDH, dirigido a brindar asistencia económica a las presuntas víctimas que carecen de recursos suficientes para sufragar los gastos del litigio ante la Corte IDH, garantizando su acceso a la justicia en términos igualitarios. Los recursos destinados para este mecanismo son limitados, depende de capital voluntario de fuentes cooperantes y del aporte de un Estado miembro de la OEA, así como de los reintegros que hagan los Estados responsables. 
cambio, un modelo como el del SIDH, en el que se impone a las autoridades nacionales las medidas indicadas en la sentencia de la Corte IDH, puede producir un efecto inverso, lo que produce el rechazo de la medidas y da lugar a argumentos sobre la falta de comprensión del contexto político y jurídico del país por parte del Tribunal, que podría, en tal caso, ver perjudicada su autoridad (Issaeva, Sergeeva y Suchkova, 2011). Este último caso es el que podría estar experimentando la Corte IDH con su actual modelo de supervisión de sentencias a partir de las reacciones de algunas cortes nacionales (Contesse, 2019).

\section{Experiencias nacionales de implementación de sentencias internacionales}

El derecho internacional de los derechos humanos reconoce una libertad configurativa a los Estados para determinar cuál será el mecanismo para implementar estas decisiones internacionales. En algunos casos existen mecanismos institucionales y legales expresamente previstos para sustanciar la ejecución de las decisiones de la Corte IDH. En otros casos, su ejecución se ha alcanzado a través de decisiones judiciales de las cortes nacionales, de acuerdo con las particularidades de cada regulación nacional (Landa, 2017: 378). De esta manera, los Estados cuentan mecanismos no homogéneos de diferente índole que dotan de fuerza ejecutiva a las medidas de reparación dictadas por la Corte IDH.

Experiencias de este tipo son muy pocas en la región, pero se pueden identificar dos modelos: el primero, que da prioridad a la obligación internacional del Estado que nace con la decisión del organismo internacional; ${ }^{26} \mathrm{y}$ el segundo, que privilegia los derechos individuales o colectivos de las víctimas de la violación a los derechos humanos por la que el Estado ha sido declarado responsable internacionalmente. ${ }^{27}$

A continuación, se presentan algunos países de la región que cuentan con mecanismos para implementar las decisiones de la Corte IDH. Se abordarán de forma breve los aspectos normativos, institucionales y procedimentales para materializar las sentencias, y no se incluirán los pronunciamientos de tribunales nacionales respecto de la recepción de tales decisiones.

26. Este proceso interno se instaura por vía de una ley o un derecho, bajo la responsabilidad de un determinado órgano del Estado, que debería adoptar todas las medidas necesarias para el cumplimiento de la obligación internacional. El proceso inicia con independencia de si lo solicita la víctima. Además, analiza de manera general la situación de derechos humanos y no solo el caso en concreto.

27. Este proceso interno reconoce un derecho de origen supranacional de la víctima y le proporciona un proceso para que inicie su reclamo ante las autoridades nacionales. Es un trámite que depende en forma directa de las víctimas declaradas en el procedimiento internacional, y solo abarca a éstas. Normalmente se inicia ante el Poder Judicial y el Poder Ejecutivo es el que ejecuta lo ordenado por el primero. 


\section{Costa Rica}

Costa Rica tiene la particularidad de que en su territorio se encuentra asentada la sede de la Corte IDH. Asimismo, dentro de sus tradiciones se encuentra la de mantener gobiernos democráticos ininterrumpidos, lo que lo distingue de los países de la región. De esta manera, cuenta con un convenio entre el gobierno y la Corte IDH, que reconoce que las resoluciones dictadas por la Corte IDH que sean comunicadas a las autoridades administrativas o judiciales nacionales, tendrán la misma fuerza ejecutiva y ejecutoria que las dictadas por los tribunales costarricenses. ${ }^{28}$ Cuenta con una institucionalidad adscrita al Ministerio de Relaciones Exteriores y Culto, denominada "Comisión interinstitucional para el seguimiento e implementación de las obligaciones internacionales de derechos humanos», para coordinar la implementación en el ámbito nacional de las obligaciones internacionales en derechos humanos, entre éstas, las sentencias de la Corte IDH (artículo 2 del Decreto Presidencial 36776-RE, del 9 de agosto de 2011). Se encuentra constituida por representantes de las distintas instituciones públicas, incluyendo ministerios y entes autónomos, relacionadas con la aplicación de los derechos humanos (artículo 5 del Decreto Presidencial 36776-RE).

Esta forma de regular la implementación de las sentencias interamericanas en el ámbito nacional no distingue entre medidas de compensación económica o de otro tipo. Asimismo, contempla la posibilidad de coordinarse con otros actores estatales diferentes al Poder Ejecutivo, ya sea como apoyo u observadores, con la posibilidad de solicitar información de importancia y coadyuvar en la implementación de las obligaciones internacionales, de conformidad con sus mandatos y sus respectivos ámbitos de acción.

\section{Perú}

Este país ha logrado avanzar en el cumplimiento de las sentencias internacionales a partir de la cantidad de casos sometidos y resueltos en su contra, con 36 sentencias condenatorias. De esta manera, reconoce constitucionalmente el derecho de la ciudadanía a recurrir a los tribunales u organismos internacionales constituidos según tratados o convenios de los que es parte (artículo 205 de la Constitución Política de Perú de 1993). Además, cuenta con una ley específica que regula el procedimiento de ejecución de sentencias emitidas por tribunales supranacionales. Esta ley declara de interés nacional el cumplimiento de las sentencias dictadas en los procesos seguidos contra el Estado peruano en tribunales constituidos por tratados en los que el Perú es parte. ${ }^{29}$

28. Artículo 27 del Convenio entre el gobierno de la República de Costa Rica y la Corte Interamericana de Derechos Humanos, 9 de septiembre de 1983, suscrito en San José, Costa Rica.

29. Artículo 1 de la Ley 27.775 que regula el procedimiento de ejecución de sentencias emitidas por 
Los procedimientos se encuentran a cargo del Poder Judicial previa comunicación del Ministerio de Relaciones Exteriores. Dentro de éstos se encuentra la ejecución de pagos de suma de dinero en concepto de indemnización por daños y perjuicios a cargo del Estado, asignándoles a dichas decisiones un carácter ejecutivo en el derecho nacional y de obligatorio cumplimiento por las autoridades competentes (artículo 2, Ley 27.775). También señala un procedimiento para cumplir con las medidas no indemnizatorias: el juez que agotó la jurisdicción interna ordenará a los órganos e instituciones estatales concernidas, sea cuales fuesen, el cese de la situación que dio origen a la sentencia referida, indicando la adopción de las medidas necesarias (artículo 4).

También cuenta con un Sistema de Defensa Jurídica del Estado, que abarca tanto la sede judicial nacional como la supranacional. Dentro de sus atribuciones se encuentra la de llevar a cabo todas las acciones que permitan cumplir las sentencias recaídas en los procesos o procedimientos en que el Estado es parte. ${ }^{30}$ Cuenta con un procedimiento en la atención de las denuncias en materia de derechos humanos y una asesoría legal especializada, además de la posibilidad de suscribir acuerdos de solución amistosa sin restricciones en la materia. ${ }^{31}$

\section{Colombia}

Colombia es otro país que ha avanzado en la materia al ser objeto de varias sentencias dictadas por el tribunal interamericano, con 17 sentencias condenatorias. Cuenta con una ley específica que regula mecanismos que facilitan el cumplimiento de las decisiones de organismos internacionales a través de un procedimiento que hace efectivo el pago de indemnizaciones compensatorias a las víctimas de violaciones de derechos humanos. Esta norma obliga al gobierno a pagar las indemnizaciones de los daños o perjuicios causados por violaciones de los derechos que se hayan declarado, o llegaren a declararse, en decisiones expresas del Comité de Derechos Humanos y de la Comisión Interamericana de Derechos Humanos, previa realización de un trámite previsto en la ley. ${ }^{32} \mathrm{Si}$ bien este marco legal es relevante para lograr el respeto de los derechos humanos, se refiere solamente a las resoluciones que emiten los órganos internacionales cuasijurisdiccionales de derechos humanos, por lo que no comprende las sentencias de la Corte IDH.

A nivel institucional, este país cuenta con un Grupo Interno de Trabajo de Segui-

tribunales supranacionales, del 27 de junio de 2002.

30. Artículo 7, letra m) del Decreto Legislativo 1.068, que crea el Sistema de Defensa Jurídica del Estado, del 27 de junio de 2008.

31. Artículos 28, 29 y 30 del Decreto Supremo 017-2008-JUS, que aprueba el Reglamento del Decreto Legislativo 1.068.

32. Artículos 1 y 2 de la Ley $288 / 96$, que regula el procedimiento para la indemnización de víctimas de violaciones de derechos humanos, del 5 de julio de 1996. 
miento a las Órdenes y Recomendaciones de Órganos Internacionales en Materia de Derechos Humanos, adscrito al Ministerio de Relaciones Exteriores, con el propósito de hacer de manera eficiente y articulada con las demás entidades estatales el seguimiento al cumplimiento de las sentencias de la Corte IDH (Resolución 5.674 de 2015). Este grupo lleva a cabo acciones para la ejecución e implementación de las medidas, recomendaciones y órdenes de los órganos internacionales, seguimiento a los procesos de indemnización, participación en audiencias, reuniones de trabajo y sesiones relativas al estado de cumplimiento de las sentencias en materia de derechos humanos.

\section{Chile}

Chile no cuenta con una ley específica para la implementación de sentencias internacionales, lo que implica estudiar vías alternativas que posibiliten el cumplimiento del fallo. Sin embargo, cuenta con normativa general que establece bases mínimas para hacer esta tarea. Por una parte, al Ministerio de Relaciones Exteriores le corresponde coordinar las actividades de los distintos ministerios y organismos públicos en aquellos asuntos que inciden en la política exterior, como las obligaciones provenientes de organismos internacionales de derechos humanos. ${ }^{33}$ Para ello, se cuenta con una «Comisión coordinadora para dar cumplimiento a las obligaciones del Estado en materia de derecho internacional de los derechos humanos», que sirve de instancia de coordinación, según los requerimientos internacionales, en la entrega de antecedentes que deben aportar los organismos públicos para elaborar las respuestas que el Estado, conformado por diversas instancias de gobierno. ${ }^{34}$

Por otra parte, la Subsecretaría de Derechos Humanos del Ministerio de Justicia y Derechos Humanos, presta asesoría técnica al Relaciones Exteriores en los procedimientos ante los tribunales y órganos internacionales de derechos humanos, y colabora en la elaboración y seguimiento de sentencias internacionales en que Chile sea parte, además de la implementación, según corresponda, de las resoluciones y recomendaciones originadas en el SIDH (artículo 8, literal e y $\mathrm{f}$ de la Ley 20.885).

El Estado chileno cumple con las diferentes medidas de reparación ordenadas por la Corte IDH a través de los procedimientos internos existentes en la mayoría de los casos. Para efectuar el pago de indemnización y reintegro de costas y gastos, el Ministerio de Justicia y Derechos Humanos dicta una resolución exenta para el cum-

33. Artículo 1 del Decreto 161, que fija el Estatuto Orgánico del Ministerio de Relaciones Exteriores, del 31 de marzo de 1978.

34. Artículo 1 del Decreto 323, que Crea la Comisión Coordinadora para dar cumplimiento a las obligaciones del Estado de Chile en materia de derecho internacional de los derechos humanos, del 6 de diciembre de 2006. 
plimiento de sentencias ejecutoriadas que condenan al Fisco, la que finalmente es materializada por la Tesorería General de la República. ${ }^{35}$ Las medidas no económicas se implementan a partir de la legislación aplicable para cada caso, ya sea activando a ministerios u otro órgano del Estado.

\section{Reflexiones a partir del proceso de reforma del SEDH}

El proceso de reforma iniciado en Europa (Interlaken, Esmirna, Brighton, Bruselas y Copenhague) orientado a garantizar al largo plazo la eficacia del SEDH y la aplicación de la CEDH, puede arrojar ciertas lecciones al SIDH para la supervisión de la ejecución de las sentencias emitidas por la Corte IDH.

En primer lugar, a partir de la entrada en vigor del Protocolo 11, del 1 de noviembre de 1998, el TEDH se renovó como mecanismo de protección de los derechos humanos. Fusionó en una institución los dos entes Comisión y Tribunal, lo que ahorra recursos financieros y humanos, gana permanencia y acelera la tramitación de peticiones, además de dotar de un acceso directo a los particulares a la jurisdicción internacional (Pastor Ridruejo, 2001). En segundo lugar, el proceso ha proporcionado un diálogo constructivo sobre cómo reforzar la capacidad nacional para ejecutar sentencias de muchos Estados y generar más diálogo y sentido de responsabilidad compartida entre los involucrados. En tercer lugar, se ha impulsado la reglamentación de un diálogo directo entre el TEDH y los tribunales nacionales, a través de la suscripción de un protocolo que aún no entra en vigor. En cuarto lugar, el proceso de reforma también ha puesto de relieve la mejora de la financiación del SEDH. En quinto lugar, ha fomentado la estrecha relación entre fijación de normas, la supervisión y la cooperación como medio para la aplicación de la CEDH y las sentencias del TEDH. En sexto lugar, se le da contenido al principio básico de la responsabilidad compartida sobre el que descansa el respeto de la CEDH. Por último, el proceso ha reforzado la subsidiariedad y ha mejorado la capacidad nacional para aplicar la CEDH.

Tomando la experiencia europea, sostenemos que el reto para avanzar en la garantía de los derechos humanos es robustecer los sistemas de protección de derechos humanos tanto a nivel internacional como doméstico. De acuerdo con el principio de subsidiariedad del SIDH, los Estados partes de la CADH son garantes principales de la $\mathrm{CADH}$ y, por tanto, también asumen de igual manera, en conjunto, la responsabilidad de velar por la integridad de la CADH y la ejecución de las sentencias de la Corte IDH (Cançado Trindade, 2003: 63-64). Así, para alcanzar el objeto y fin de la $\mathrm{CADH}$, y de la jurisdicción de la Corte IDH —es decir, impartir justicia dirigida a la eficaz protección de los derechos humanos-, debiese trascender la supervisión

35. Artículo 2 del Decreto 3.346, que fija el texto de la Ley Orgánica del Ministerio de Justicia y Derechos Humanos, del 22 de mayo de 1980. 
de cumplimiento de sentencias que actualmente se encuentra a cargo del Tribunal Interamericano.

Hay que reconocer que tanto en el SIDH como en el derecho interno de los Estados existen vacíos normativos en materia de supervisión de cumplimiento y ejecución de sentencias, los cual es necesario subsanar para su perfeccionamiento, en dos direcciones: la primera, dirigida a modificar el mecanismo de supervisión de cumplimiento de sentencias a cargo de la Corte IDH. De acuerdo con una lectura más detenida de la $\mathrm{CADH}$, la norma dispone únicamente que ese Tribunal Interamericano «señalará [a la Asamblea General de la OEA] los casos en que un Estado no haya dado cumplimiento a sus fallos» (artículo 65). Es decir, la normativa convencional solo establece un deber de informar, mas no atribuye una competencia adicional de supervisión de cumplimiento de sentencias.

Se visualiza la oportunidad para que la OEA adopte medidas para crear un órgano permanente político y diplomático con representación de los Estados que se haga cargo de la supervisión de los fallos, o dotar a los órganos actuales de poderes y competencias específicas y expresas para efectuar esa labor, con un procedimiento detallado que asegure su cumplimiento total. En ese sentido, debiese adoptarse una postura del principio de subsidiariedad que reconozca un margen de apreciación nacional en el cumplimiento de las obligaciones que establece la CADH; y establecer un diálogo para mejorar las capacidades de los Estados para ejecutar las sentencias, a partir de una corresponsabilidad en la búsqueda de soluciones a la falta de efectividad del SIDH. Así, la Corte IDH podría hacer más partícipes a los Estados en la búsqueda de soluciones a las denuncias presentadas que puedan ser adaptadas a las circunstancias nacionales, y en casos excepcionales o incumplimiento, señalar la medida de reparación apropiada.

En segundo lugar, los fallos se verían garantizados si los esfuerzos regionales se articulan con órganos públicos y leyes específicas de ejecución de los fallos interamericanos en la esfera doméstica de los Estados que reconocen su jurisdicción vinculante y obligatoria. Es decir, reforzar el diseño institucional nacional a cargo de la protección de los derechos humanos (Simmons, 1998), que garantice seguridad jurídica a través de un marco jurídico que regule el procedimiento y asigne competencias para prever la manera en que los órganos públicos aplicarán las fuentes del derecho internacional en el diseño de políticas o en la resolución de casos concretos.

\section{A modo de conclusión}

Podemos concluir que los fallos de los tribunales regionales de derechos humanos tienen carácter obligatorio y definitivo, pero no son ejecutables, ya que requieren la colaboración del Estado para hacerla cumplir en el ámbito nacional. En el caso europeo, las sentencias del TEDH son por general declarativas, por lo que reconocen un 
margen de apreciación a los Estados en la determinación de las medidas de reparación, y de manera excepcional, el TEDH interviene fijando una medida satisfactoria. La ejecución de sentencias se encuentra a cargo de un órgano político con representación de todos los Estados del Consejo de Europa, y su cumplimiento es frecuente. Por el contrario, las sentencias de la Corte IDH desafían el modelo europeo, al aplicar en forma directa las normas del derecho internacional para ordenar las reparaciones, exigiendo su ejecución a través de un mecanismo de supervisión que se encuentra a su cargo, sin que la normativa convencional lo señale de forma expresa, registrando un bajo cumplimiento total de las sentencias.

De esta forma, se observa una paradoja. Por un lado, los órganos interamericanos son proactivos para la generación de mecanismos y herramientas para promover la eficacia de la aplicación de la CADH y los fallos de la Corte IDH. Pero, por otro lado, los Estados no se esfuerzan en hacer lo suyo para reforzar el SIDH a través del ejercicio de su potestad normativa, con la aprobación de nuevos instrumentos jurídicos que lo hagan más eficiente. Esta situación incentiva la labor interpretativa de la Corte IDH en dictar sentencias con medidas de reparación más detalladas y precisas, y justifica la labor de supervisión de su cumplimiento. En este aspecto será importante promover una reforma, ya sea a la propia $\mathrm{CADH}$, o con la elaboración de un protocolo adicional específico para la ejecución de sentencias que tome en cuenta un órgano permanente político o diplomático en el que fluya un diálogo constructivo con los Estados, con tal de reducir las brechas de implementación de sentencias interamericanas.

Desde el punto de vista de la responsabilidad internacional del Estado, no se puede esgrimir como excusa para eludir el cumplimiento de los fallos internacionales la separación de poderes o la ausencia de marcos legales que permitan satisfacer el cumplimiento de sentencias que son obligatorias. No obstante, desde el punto de vista de los Estados, es imprescindible asegurar la seguridad jurídica, por tanto, se requiere de una regulación de procedimientos internos de ejecución de sentencias, con tal que se emitan normas que establezcan una tramitación expedita y eficaz para el cumplimiento de las obligaciones internacionales de derechos humanos, incluidas las sentencias.

Los casos seleccionados de experiencias nacionales evidencian que el cumplimiento de las sentencias de la Corte IDH es complejo. En la mayoría de los países de la región, las entidades gubernamentales encargadas de ejecutar las sentencias tienen que impulsar procesos de coordinación que involucran a diferentes órganos del Estado y con resultados variados que van desde el pago de indemnizaciones, modificaciones legislativas y dejar sin efectos sentencias judiciales. Una limitante para alcanzar acuerdos es no contar con una normativa legal específica que señale con claridad los mandatos de cada una de las instituciones públicas que participan en el cumplimiento de sentencias internacionales. 
La solución a este problema partiría en incentivar a los Estados a que promuevan estas herramientas legales. Hay buenas razones para ello: en primer lugar, permite que los Estados mantengan una política consistente en honrar las obligaciones internacionales y su interpretación y aplicación, al margen de los vaivenes políticos. En segundo lugar, es una respuesta a los argumentos que pretenden evadir la responsabilidad internacional esgrimiendo razones de derecho interno. En tercer lugar, la adopción de medidas internas para ejecutar decisiones judiciales de carácter internacional se encuentra ligada a la posibilidad de que las víctimas tengan acceso a una reparación integral del daño; de esta manera, no es una posibilidad para los Estados caer en incumplimiento de las sentencias en las que ha sido condenado.

\section{Agradecimientos}

Este artículo es resultado de la participación del autor en el proyecto Desafíos Globales para la Democracia, el que forma parte del Proyecto de Internacionalización de la Investigación del Programa de Doctorado en Derecho, Universidad de Chile y Universidad de Buenos Aires.

\section{Referencias}

BASCH, Fernando, Leonardo Filippini, Ana Laya, Mariano Nino, Felicitas Rossi y Bárbara Schreiber (2010). «La efectividad del Sistema Interamericano de Protección de Derechos Humanos: Un enfoque cuantitativo sobre su funcionamiento y sobre el cumplimiento de sus decisiones». Sur: Revista Internacional de Derechos Humanos, 7 (12): 9-35. Disponible en https://bit.ly/2F6kRN8.

Bertoni, Eduardo (2016). «El Sistema Interamericano de Derechos Humanos SIDH - y la (¿real?) falta de apoyo regional». Iuris Dictio, 20: 87-104. DOI: 10.18272/iu.v20i20.906.

Cançado Trindade, Antonio (2003). «El derecho de acceso a la justicia internacional y las condiciones para su realización en el sistema interamericano de protección de los derechos humanos». Revista Instituto Interamericano de Derechos Humanos, 37: 53-83. Disponible en https://bit.ly/35d2DUB.

Contesse, Jorge (2016). «Contestation and deference in the Inter-American Human Rights System». Law and Contemporary Problems, 79 (2): 124-145. Disponible http://bit.ly/35b9bDe.

-. (2019). «Constitucionalismo interamericano y contragolpe judicial». En Sistema Económico Latinoamericano y del Caribe (editores), Los desafíos constitucionales de la democracia social. Buenos Aires: Libraria.

Greer, Steven (2006). The European Convention on Human Rights: Achievements, problems and prospects. Nueva York: Cambridge University Press. 
Issaeva, María, Irina Sergeeva y María Suchkova (2011). «Ejecución de las sentencias del Tribunal Europeo de Derechos Humanos en Rusia: Desarrollos recientes y desafíos actuales». SUR, 8 (15): 69-91. Disponible https://bit.ly/35f2uQU.

JaChtenfuchs, Markus y Nico Krisch (2016). «Subsidiarity in global governance». Law and Contemporary Problems, 79 (2): 1-26. Disponible en http://bit. ly/2SCTLoT.

KrStiCeViC, Viviana (2003). «Líneas de trabajo para mejorar la eficacia del sistema». En Centro por la Justicia y el Derecho Internacional, Retos para el cumplimiento de las decisiones de los órganos del sistema interamericano de protección de derechos humanos. San José: Centro por la Justicia y el Derecho Internacional.

LANDA, César (2017). «Mecanismos procesales domésticos para la ejecución de las sentencias de la Corte Interamericana de Derechos Humanos». Humberto Nogueira Alcalá y Gonzalo Aguilar (editores), El parámetro del control de convencionalidad, la cosa interpretada y el valor de los estándares de la Corte Interamericana de Derechos Humanos (pp. 376-404). Buenos Aires: Triángulo.

Leite, Rodrigo (2017). "Análise dos processos e atores políticos na supervisão de sentenças da Corte Interamericana de Direitos Humanos». En Simone Viscarra (compiladora), América Latina em foco: Novas perspectivas de análise sobre a região. Porto Alegre: Terra da Ideia.

LoNDOÑo, María (2006). «El cumplimiento de las sentencias de la Corte Interamericana: Dilemas y retos». En Comisión Andina de Juristas, El Sistema Interamericano de Protección de los Derechos Humanos y los países andinos. Lima: Fundación Konrad Adenauer.

Mushkat, Roda (2009). «Dissecting international legal compliance: An unfinished odyssey». Denver Journal of International Law and Policy, 38 (1): 161-191. Disponible en http://bit.ly/37qtduX.

Koskenniemi, Martti (2006). Fragmentación del derecho internacional: Dificultades derivadas de la diversificación y expansión del derecho internacional. Informe del Grupo de Estudio de la Comisión de Derecho Internacional de Naciones Unidas. Nueva York: Naciones Unidas.

Nogueira Alcalá, Humberto (2006). «Los desafíos de la sentencia de la Corte Interamericana en el caso Almonacid Arellano». Ius et Praxis, 12 (2): 363-384. DOI: 10.4067/So718-00122006000200013.

Pastor Ridruejo, José Antonio (2001). «El Tribunal Europeo de Derechos Humanos: La reforma de la reforma». Anuario Jurídico de La Rioja, 7: 429-440. Disponible en http://bit.ly/2sxwJFg.

Pinto, Mónica (2010). «La soberanía y el nuevo orden internacional». Anuario de Filosofía Jurídica y Social, 29: 165-179.

RAz, Joseph (2009). Human rights in the New World Order. Nueva York: Columbia Public Law \& Legal Theory Working Papers. 
Rodríguez Rescia, Víctor Manuel (1998). «La ejecución de sentencias de la Corte». En J. Méndez y F. Cox (editores), El futuro del sistema interamericano de protección de los derechos humanos. San José: Instituto Interamericano de Derechos Humanos.

SAntelices, Tabata y Mayra Feddersen (2010). «Ejecución de sentencias internacionales sobre derechos humanos en Chile». Anuario de Derecho Público, 1: 92-113. Disponible en https://bit.ly/35aPnjv.

SCelle, George (1933). «Règles générales du droit de la paix». Recueil des Cours de l'Académie de Droit International, 46: 327-696.

Shelton, Dinah y Paolo Carroza (2013). Regional protection of human rights. Nueva York: Oxford University Press.

Simmons, Beth Ann (1998). «Compliance with international agreements». Annual Review of Political Science, 1: 75-93. DOI: 10.1146/annurev.polisci.1.1.75.

TEDH, Tribunal Europeo de Derechos Humanos (2017). Informe supervisión de la ejecución de sentencias y resoluciones de la Corte Europea Derechos de Humanos. Estrasburgo: Tribunal Europeo de Derechos Humanos.

Von Bogdandy, Armin (2016). "Ius constitutionale commune en América Latina: A regional approach to transformative constitutionalism». Documento de trabajo 2016-21. Heidelberg: Max Planck Gesellschaft.

ZAVERUCHA, Jorge y Rodrigo Leite (2016). «A impunidade de agentes estatais nos casos julgados pela Corte Interamericana». Revista Brasileira de Seguranca Pública, 10 (1): 88-107. Disponible en http://bit.ly/37jFEc7.

\section{Sobre el autor}

Oliver Román López Serrano es abogado salvadoreño, autorizado por la Corte Suprema de Chile. Candidato a doctor en Derecho, Universidad de Chile. Maestro en Derechos Humanos y Educación para la Paz, Universidad de El Salvador. Licenciado en Ciencias Jurídicas, Universidad Centroamericana José Simeón Cañas, El Salvador. Abogado de la Dirección de Derechos Humanos del Ministerio de Relaciones Exteriores de Chile. Su correo electrónico es oliverlopezes@yahoo.com. 
